This is the accepted version of the following article

Martin Křižan, Jaromír Vinklárek, Milan Erben, Zdeňka Růžičková, Jan Honzíček (2019). Iron(II) complex with modified bispidine ligand: Synthesis and catalytic alkyd drying. Inorganica Chimica Acta.

DOI: $10.1016 /$ j.ica.2018.11.035

This accepted version is available from URI https://hdl.handle.net/10195/74951

Publisher's version is available from: $\underline{\text { https://www.sciencedirect.com/science/article/pii/S0020169318315950 }}$

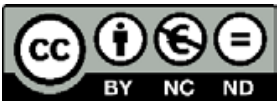

This version is licenced under a Creative Commons Attribution-NonCommercial-NoDerivatives 4.0.International. 


\title{
Iron(II) complex with modified bispidine ligand: Synthesis and catalytic performance.
}

\author{
Martin Kř̌žan ${ }^{\text {a }}$, Jaromír Vinklárek ${ }^{\mathrm{b}}$, Milan Erben ${ }^{\mathrm{b}}$, Zdeňka Růžičková ${ }^{\mathrm{b}}$, Jan Honzíček a, \\ ${ }^{a}$ Institute of Chemistry and Technology of Macromolecular Materials, Faculty of Chemical Technology, \\ University of Pardubice, Studentská 573, 53210 Pardubice, Czech Republic. \\ b Department of General and Inorganic Chemistry, Faculty of Chemical Technology, University of \\ Pardubice, Studentská 573, 53210 Pardubice, Czech Republic. \\ * Corresponding author. Tel.: +420 46603 7229; fax: +420 466037068. \\ E-mail address: jan.honzicek@upce.cz (J. Honzíček).
}

Keywords: iron; bispidine; X-ray structure; alkyd paints; autoxidation

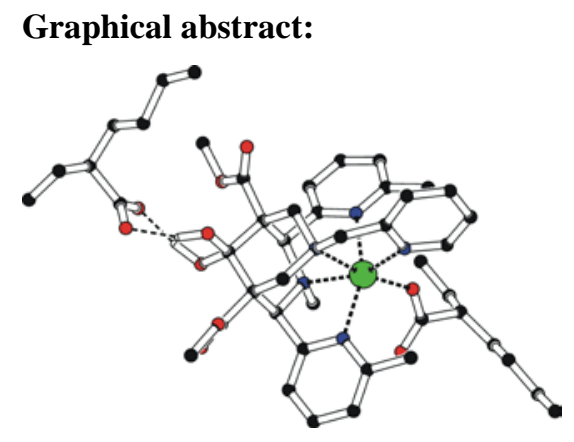

Highlights:

New iron bispidine complex was synthesized.

Crystal structure was determined by X-ray analysis.

Catalytic activity toward alkyd autoxidation was established.

\section{Abstract}

Modified iron(II) bispidine complex was synthesized and characterized by analytical methods including crystal structure determination by single crystal X-ray diffraction. Catalytic activity of title compound toward autoxidation process was established on alkyd resin of long oil length. The standardized mechanical tests as well as kinetic studies, performed on thin layers of alkyd coatings, revealed high activity at considerably lower concentrations than usual for commercial cobalt(II) 2-ethylhexanoate. Due to high solubility in non-polar solvents, title compound is applicable without necessity of pre-dissolution in polar organic solvent as in the case of parent [Fe(bispi)Cl]Cl.

\section{Introduction}

Pentadentate ligands based on diazabicyclo[3.3.1]nonane backbone (aka bispidine) attract considerable attention in the field of coordination chemistry due to specific geometric constrains in metal complexes enforcing asymmetric octahedral geometry [1]. High-valent iron bispidine complexes were explored as catalysts 
for oxidation and halogenation [2]. Low-valent [Fe $\left.{ }^{\mathrm{II}}(\mathrm{bispi}) \mathrm{Cl}\right] \mathrm{Cl}$, where bispi is dimethyl 2,4-bis(pyridin-2-yl)-3methyl-7-(pyridin-2-ylmethyl)-3,7-diazabicyclo[3.3.1]nonan-9-one-1,5-dicarboxylate, has found the application in paint producing industry as the catalyst for autoxidation [3]. Such catalyst (so-called drier) significantly reduces drying times of air-drying paints e.g. alkyd resins [4], methacrylate latexes modified with fatty acids [5] and polyurethane dispersions synthesized from cardanol [6]. [Fe $\left.{ }^{\mathrm{II}}(\mathrm{bispi}) \mathrm{Cl}\right] \mathrm{Cl}$ serves as an alternative for currently used cobalt(II) carboxylates those are under evaluation of European Chemical Agency owing to their toxic properties [7, 8]. We note that the autoxidation of alkyd resins is catalyzed also by various manganese [911], iron [12-14] and vanadium complexes [15-18]. Nevertheless, most of them still stay in early stage of the investigation or suffer from some disadvantages such as low activity at ambient temperature, intense coloration or hydrolytic instability.

The main advantage of iron bispidine compounds is high catalytic activity at about two orders of magnitude lower concentration than usual for cobalt-based driers [3, 4, 19, 20]. Furthermore, they produce films with more uniform distribution of crosslinks than in case of traditional cobalt-based driers [21]. The application of $[\mathrm{Fe}($ bispi)Cl]Cl is to some extent limited by low solubility in aprotic organic solvents that prevents its use in particular formulations (e.g. alkyd resins of long oil-length supplied in white spirit).

The aim of this study is to synthesize modified iron bispidine complex bearing 2,4-bis(6-methylpyridin-2yl)-3-methyl-7-(pyridin-2-ylmethyl)-3,7-diazabicyclo[3.3.1]nonan-9-one-1,5-dicarboxylate (Mebispi). Solubility in alkyd formulation will be further enhanced by coordination of carboxylate ligand decorated with branched alkyl tail. The catalytic performance of the synthesized compound will be determined on commercial alkyd resin of long oil-length (S60) by standard mechanical tests. Kinetic parameters of the autoxidation process in given formulation will be determined be time-resolved infrared spectroscopy.

\section{Results and discussion}

\subsection{Synthesis and characterization of modified iron bispidine complex}

Modified bispidine ligand Mebispi (2) was prepared by two one-pot Mannich condensation steps in line with published procedure, Scheme 1 [22, 23]. In the first step, dimethyl-3-oxoglutarate reacts with methylamine and two equivalents of 6-methylpyridine-2-carboxaldehyde to give substituted piperidone 1. ${ }^{1} \mathrm{H}$ NMR spectrum, measured in chloroform-d, proves appearance of enol and keto form in approximate molar ratio 4:1. The enol form (1-enol) shows singlet of -OH group at $12.41 \mathrm{ppm}$ and characteristic pattern of piperidine core consisting of singlet at $4.81 \mathrm{ppm}$ and two dublets at 4.47 and $4.17 \mathrm{ppm}\left({ }^{3} \mathrm{~J}=9.3 \mathrm{~Hz}\right)$. In the keto-form (1-keto), four hydrogen atoms of piperidine core give two dublets at 4.51 and $4.05 \mathrm{ppm}\left({ }^{3} \mathrm{~J}=5.9 \mathrm{~Hz}\right)$ due to higher symmetry being also apparent from equivalency of ester or pyridyl groups.
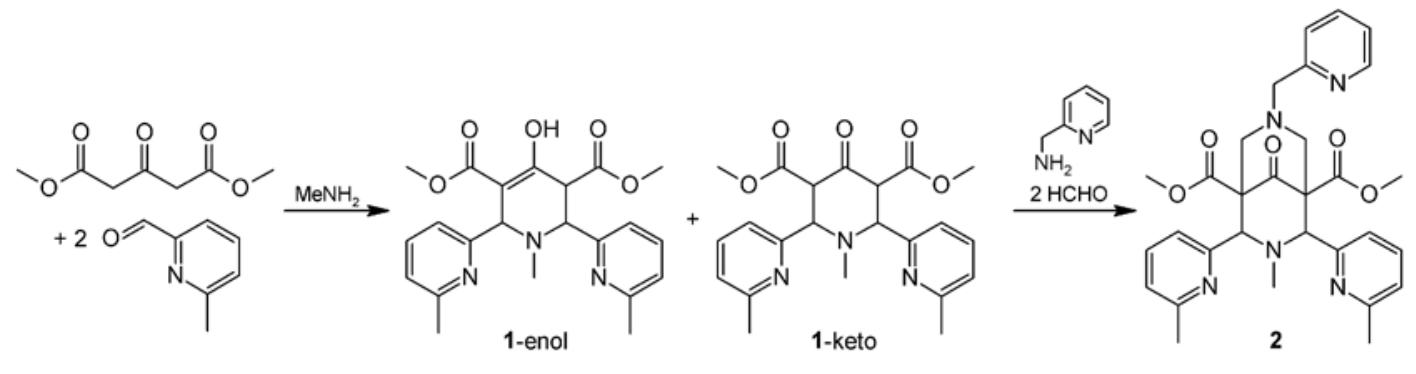

Scheme 1. Synthesis of modified bispidine ligand 2 
Solid-state structure of enol form was determined by X-ray diffraction analysis. Piperidine core adopts an envelope conformation with nitrogen atom localized 0.520(1) $\AA$ above plane defined by C1, C2, C3 and C5. Enol tautomer is significantly stabilized by strong intramolecular hydrogen bond $-\mathrm{O} 1-\mathrm{H} \cdots \mathrm{O} 2=($ Figure 1$)$. Substituted pyridines adopt anti-configuration, which was previously observed for several congeners of 1 [24, 25].

Vibrational spectra of $\mathbf{1}$ also prove the presence of enol form in both solid state and solution. It is evident from detailed analysis of the spectral region 1760-1540 $\mathrm{cm}^{-1}$. Infrared spectrum shows well-distinguished strong bands at $1621 \mathrm{~cm}^{-1}$ and $1650 \mathrm{~cm}^{-1}$. The former vibration mode appears also in Raman spectrum as strong line at $1623 \mathrm{~cm}^{-1}$ and it has been assigned to $\mathrm{C}=\mathrm{C}$ stretching mode of enolic moiety. The IR absorption at $1650 \mathrm{~cm}^{-1}$ has no corresponding line in Raman spectra and thus it was assigned to intramolecularly hydrogen-bonded C=O vibration. This band is characteristic for enolized forms of various 1,3-dicarbonyl compounds [26].

Vibrational spectra of $\mathbf{1}$, measured in solid state, also imply formation of enol form. It is evident mainly from detailed analysis of the spectral region 1760-1540 $\mathrm{cm}^{-1}$. Infrared spectrum shows well-distinguished band of $\mathrm{C}=\mathrm{C}$ stretching at $1621 \mathrm{~cm}^{-1}(\mathrm{~m}-\mathrm{s})$ and $\mathrm{OH}$ bending at $1650 \mathrm{~cm}^{-1}(\mathrm{~s})$. The former vibration mode appears also in Raman spectrum as strong band at $1623 \mathrm{~cm}^{-1}$ due to high polarizability of the carbon-carbon double bond while the later one in Raman inactive. This region further shows $\mathrm{C}=\mathrm{O}$ stretching absorption typical for ester groups (IR/Ra: 1726/1730 $\mathrm{cm}^{-1}$ ) and C=C stretching bands of aromatic ring attributed to pyridine moiety (IR/Ra: $\left.1590 / 1592 \mathrm{~cm}^{-1}, 1574 / 1577 \mathrm{~cm}^{-1}\right)$.

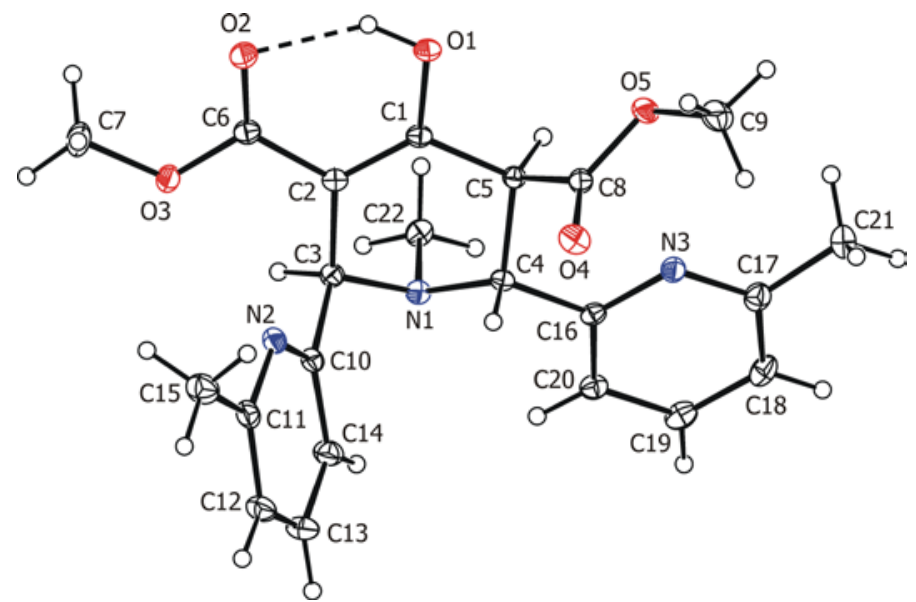

Fig. 1. ORTEP drawing of the molecule 1-enol. The labeling scheme for all non-hydrogen atoms is shown. Thermal ellipsoids are drawn at the $30 \%$ probability level.

In the second reaction step, $\mathbf{1}$ is condensed with 2-(aminomethyl)pyridine and formaldehyde to give Mebispi (2), which purity was checked by spectroscopic methods. Multinuclear NMR spectroscopy proves appearance of 2 in $C_{\mathrm{s}}$ symmetric keto form. In ${ }^{1} \mathrm{H}$ NMR spectrum, bispidine core gives one singlet at $4.63 \mathrm{ppm}(2 \mathrm{H})$ and two dublets at 3.03 and $2.62 \mathrm{ppm}\left({ }^{2} J=12.0 \mathrm{ppm}, 2 \times 2 \mathrm{H}\right)$. The appearance of keto form is also evidenced by infrared and Raman spectra. In spectral region $1760-1540 \mathrm{~cm}^{-1}$, two bands at high wavenumbers (IR/Ra: $1731 / 1734 \mathrm{~cm}^{-1}$ and $1721 / 1724 \mathrm{~cm}^{-1}$ ) were assigned to $\mathrm{C}=\mathrm{O}$ stretching modes of keto and ester groups. At lower wavenumbers, only bands of aromatic C=C vibrations appear (IR/Ra: 1590/1592 $\mathrm{cm}^{-1}$ and 1574/1577 $\mathrm{cm}^{-1}$ ) but no band assignable for enol moiety or hydrated keto group has been found. 


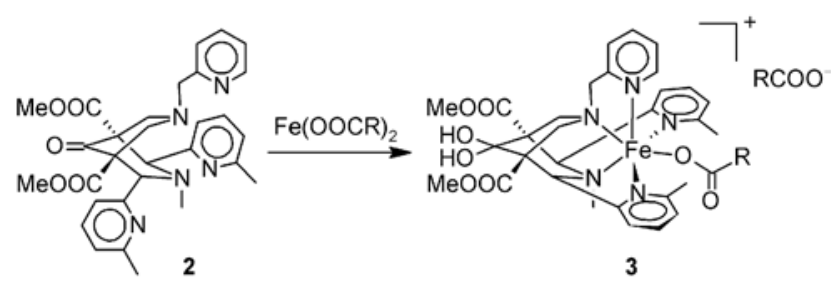

Scheme 2. Synthesis of bispidine complex 3 ( $\mathrm{R}=3$-heptyl)

The title complex [Fe $\left.{ }^{\mathrm{II}}(\mathrm{Mebispi}) \mathrm{OOCR}\right][\mathrm{OOCR}]$ ( $\mathrm{R}=3$-heptyl, 3) was prepared by ligand exchange reaction, Scheme 2, starting from iron(II) 2-ethylhexanoate readily available from iron(II) hydroxide and 2ethylhexanoic acid [19]. As observed before, coordination of the first-row transition metal led to hydration of keto group as the reaction was not done under strictly anhydrous conditions [27]. The hydration is favorable due to steric enforced $s p^{3}$-hybridization of the carbon atom in constrained geometry of the cage structure [27-29]. The assembly of $\left[\mathrm{Fe}^{\mathrm{II}}(\mathrm{Mebispi}) \mathrm{OOCR}\right]^{+}$was evidenced by electrospray ionization mass spectrometry. The peak at $m / z=760$ was assigned to cationic title compound $[\mathrm{M}]^{+}$while the base peak at $\mathrm{m} / \mathrm{z}=742$ is product of water elimination $\left[\mathrm{M}-\mathrm{H}_{2} \mathrm{O}\right]^{+}$from hydrated keto group (100\%). We note that the title compound is paramagnetic, which precludes the use of multinuclear NMR spectroscopy for routine characterization. Magnetic moment $\left(\mu_{\text {eff }}\right.$ = 4.92 B.M.), measured at room temperature, implies appearance of octahedral iron(II) species in high-spin state $(S=2)$. The obtained value nears the data reported previously for similar iron(II) complexes [30]. The electronic spectrum of 3 consists of three bands at 230, 264 and $400 \mathrm{~nm}$, the latter being responsible for bright yellow colour of the complex. Two bands in UV region are due to ligand centered $\pi-\pi^{*}$ transitions ( $c f$. UV-Vis spectra 1 and 2 in Experimental section) whereas low energy band $\left(\varepsilon=3200 \mathrm{M}^{-1} \cdot \mathrm{cm}^{-1}\right)$, is attributable to a metal-to-ligand charge transfer. The appearance of UV-Vis spectrum of $\mathbf{3}$ is characteristic for high-spin iron(II) complexes with distorted octahedral geometry [31].

Infrared spectrum of 3 shows very intense band at $1728 \mathrm{~cm}^{-1}$ (not active in Raman) due to carbonyl stretching of ester groups of Mebispi ligand. Hydrated carbonyl function gives two very broad absorptions at 2650 and $2550 \mathrm{~cm}^{-1}$ witnessing for the presence of strong hydrogen bond in the molecule. Medium IR band (broadened and red-shifted by $9 \mathrm{~cm}^{-1}$ in the solution; inactive in Raman) at $1626 \mathrm{~cm}^{-1}$ has been assigned to antisymmetric stretching vibration of 2-ethylhexanoate anions. The ring stretching modes of pyridine fragments appear at slightly higher wavenumber (strong line at $1602 \mathrm{~cm}^{-1}$ in both Raman and IR) than in free 2 probably due to coordination toward iron(II) cation via pyridine nitrogen atom.

Complex cation has distorted octahedral structure, in which five coordination sites of iron(II) are occupied with nitrogen atoms of Mebispi and remaining position with oxygen atom of $\kappa^{1}$-coordinated 2-ethylhexanoate (Figure 2). Fe-N bond distances vary between 2.185 and 2.349(2) $\AA$. Fe-O distance [1.993(2) $\AA$ ] is close to the value previously reported for parent bispidine complex [Fe(bispi)OOCR][OOCR] [19]. Iron(II) atom lays almost within the plane defined by carbon atom C21 nitrogen donor atoms N2, N5, which splits Mebispi ligand into two chemically equivalent parts. The distance between the iron and this plane is 0.065(1) $\AA$. The pyridyl group (Ring $_{\mathrm{C} 1-\mathrm{N} 1}$ ) is twisted by $26.37(14)^{\circ}$ with respect to this plane. Remaining pyridine groups (Ring ${ }_{\mathrm{C} 7-\mathrm{N} 3}$ and Ring $\left._{\mathrm{C} 13-\mathrm{N} 4}\right)$ are also tilted as evident from large angles between $\mathrm{Fe}-\mathrm{N}$ and pyridine ring plane $[\mathrm{Fe}-\mathrm{N} 3-\mathrm{P}]_{\mathrm{C} 7-\mathrm{N} 3}=$

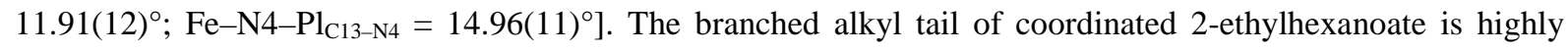
disordered due to presence of two chiral forms in one crystallographic position. Nevertheless, the coordination sphere of iron is well described due to high rigidity of Mebispi ligand. 2-Ethylhexanoate counterion is connected 
to hydroxy groups of the complex cation via two hydrogen bonds $[\mathrm{O} 1 \cdots \mathrm{O} 8=2.610(4) \AA$ and $\mathrm{O} 11 \cdots \mathrm{O} 9=$ 2.674(3) §] forming unusual 8-membered cycle, which probably stabilizes geminal diol moiety (Figure 3).

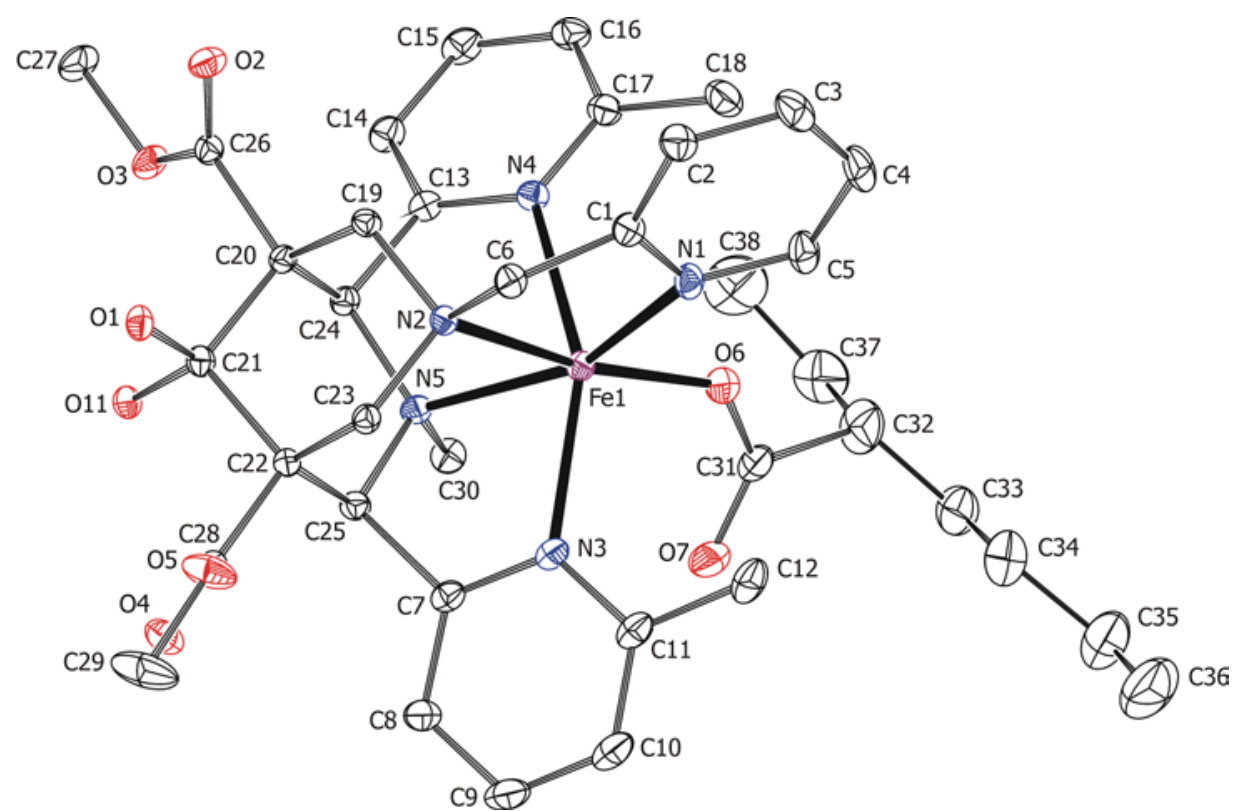

Fig. 2. ORTEP drawing of the $\left[\mathrm{Fe}^{\mathrm{II}}(\mathrm{Mebispi}) \mathrm{OOCR}\right]^{+}(\mathrm{R}=3$-heptyl $)$ present in crystal structure of 3·Et 2 O. The labeling scheme for all non-hydrogen atoms is shown. Thermal ellipsoids are drawn at the $30 \%$ probability level. Hydrogen atoms are omitted for clarity. Only one of disordered tails of 2-ethylhexanoate is shown. Selected bond lengths ( $\AA$ ): Fe1-N1 2.194(3), Fe1-N2 2.313(2), Fe1-N3 2.222(2), Fe1-N4 2.349(2), Fe1-N5 2.185(3), Fe1-O6 1.993(2).

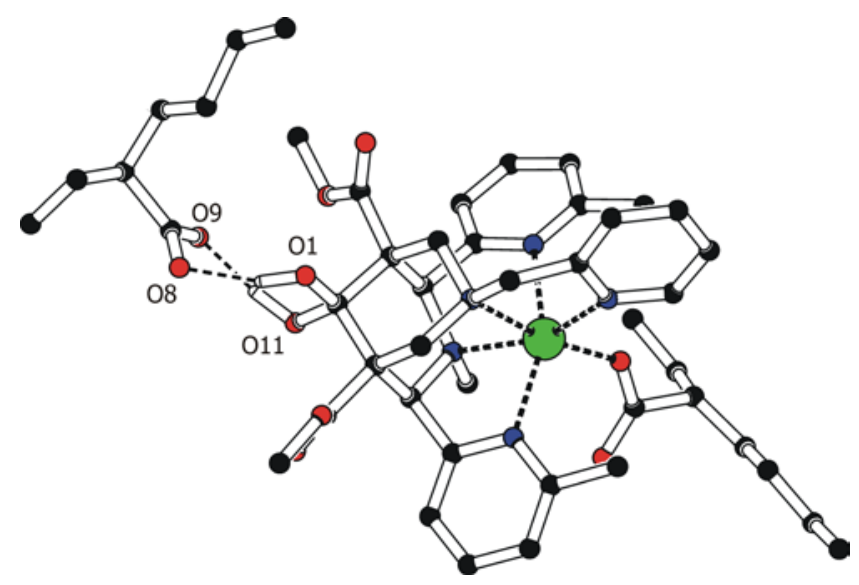

Fig. 3. Hydrogen bonding in crystal structure of $3 \cdot \mathrm{Et}_{2} \mathrm{O}$. Only hydrogen atoms are involved in hydrogen bonds are shown for clarity

\subsection{Drying activity of 3}

Catalytic performance of $\mathbf{3}$ was studied in solvent-borne alkyd resin of long oil-length modified with soybean oil (S60) using standard mechanical tests suitable for determination of drying times of the formulations [32] and relative hardness of the final coatings [33]. Satisfactory solubility of the title compound in the formulation of $\mathbf{S 6 0}$ enables its application in wide concentration range, from $1 \times 10^{-1}$ to $5 \times 10^{-4}$ wt.\% of the metal in dry matter content, without necessity of pre-dissolving in polar organic solvents as usual to lower soluble driers. 
The determination of drying times reveals high activity of 3 in concentrations $1 \times 10^{-1}$ to $5 \times 10^{-3}$ wt.\% (runs A-D), see Table 1. At this range, the total-dry time $\left(\tau_{2}\right)$ does not exceed $24 \mathrm{~h}$ and final films stay flat without apparent visual defects. Both tack-free time $\left(\tau_{1}\right)$ and total-dry time $\left(\tau_{2}\right)$ smoothly increase with decreasing metal concentration implying absence of overdose effects that usually appears as retardation of drying process at high metal concentrations due to formations of a thin skin on the surface, which restricts oxygen penetration into coating and thereby decelerates the autoxidation process.

The catalytic activity of $\mathbf{3}$ is considerably less dependent on metal concentration than in the case of commercial cobalt(II) 2-ethylhexanoate. Although both driers show similar values of $\tau_{2}$ at high metal concentration ( $c f$. runs $\mathbf{A}$ and $\mathbf{C o - A}$ in Table 1), lowering of metal content to $1 \times 10^{-3}$ wt.\% leads to deterioration of curing process only in formulation treated with cobalt compound while $\mathbf{3}$ is, at the same metal concentration, still highly active (run $\mathbf{C}$ in Table 1). Further advantage of the coatings treated with $\mathbf{3}$ is faster rise of their relative hardness during first few days of curing. They reach $15 \%$ of a glass standard within $\sim 5$ days while those treated with cobalt 2-ethylhexanoate need $\sim 10$ days to reach the same value. We note that the coatings treated with 3 show generally lower final hardness than usual for cobalt-based driers [3]. Nevertheless, our measurements reveal values acceptable for universal outdoor applications ( $H_{\text {rel,100d }}$ for runs A-D in Table 1$)$.

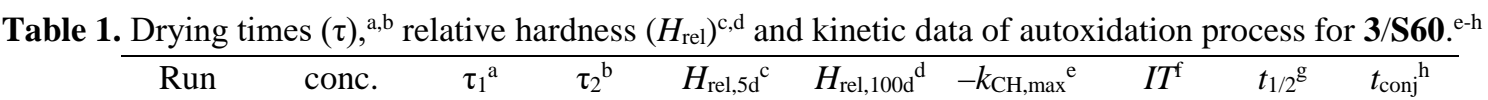

\begin{tabular}{cccccccccc} 
& $(\mathrm{wt} . \%)$ & $(\mathrm{h})$ & $(\mathrm{h})$ & $(\%)$ & $(\%)$ & $\left(\mathrm{h}^{-1}\right)$ & $(\mathrm{h})$ & $(\mathrm{h})$ & $(\mathrm{h})$ \\
\hline $\mathbf{A}$ & $1 \times 10^{-1}$ & 1.8 & 3.1 & 17.4 & 30.2 & 0.82 & 0.6 & 1.4 & 1.6 \\
$\mathbf{B}$ & $5 \times 10^{-2}$ & 2.7 & 5.0 & 16.3 & 30.0 & 0.40 & 1.2 & 3.0 & 3.2 \\
$\mathbf{C}$ & $1 \times 10^{-2}$ & 5.4 & 7.1 & 14.3 & 27.9 & 0.20 & 2.7 & 6.4 & 6.3 \\
$\mathbf{D}$ & $5 \times 10^{-3}$ & 6.9 & 10.8 & 14.2 & 26.9 & 0.16 & 3.6 & 8.1 & 9.1 \\
$\mathbf{E}$ & $1 \times 10^{-3}$ & 23.1 & $>24$ & 14.1 & 23.8 & 0.09 & 16.1 & 25.9 & 27.1 \\
$\mathbf{F}$ & $5 \times 10^{-4}$ & $>24$ & $>24$ & 14.0 & 23.0 & 0.08 & 36.6 & 46.6 & 48.2 \\
Co-A $^{\mathrm{i}}$ & $1 \times 10^{-1}$ & 0.8 & 4.6 & $16.0^{\mathrm{j}}$ & 39.4 & 1.56 & $<0.1$ & $-{ }^{\mathrm{k}}$ & 1.4 \\
$\mathbf{C o - B}^{\mathrm{i}}$ & $3 \times 10^{-2}$ & 1.7 & 8.5 & $14.9^{\mathrm{j}}$ & 33.5 & 0.74 & 1.9 & $-{ }^{\mathrm{k}}$ & 4.1
\end{tabular}

a Tack-free time; ${ }^{\text {b }}$ Total-dry time; ${ }^{\text {c }}$ Relative hardness after 5 days of curing; ${ }^{\mathrm{d}}$ Final relative hardness measured after 100 days of curing; ${ }^{\mathrm{e}}$ Maximum oxidation rate constant $\left(k_{\mathrm{CH}, \max }\right)$; ${ }^{\mathrm{f}}$ Induction time (IT) has been determined graphically as intersection of tangential lines extending the curve before and after knee point; ${ }^{g}$ Half-life $\left(t_{1 / 2}\right)$ has been determined as point when $50 \%$ of active $\mathrm{CH}$ bonds is consumed; ${ }^{\mathrm{h}}$ Drying time in which the band at $989 \mathrm{~cm}^{-1}$ reached maximal absorbance; ${ }^{\mathrm{i}}$ Data taken from ref. [16]; ${ }^{j}$ Relative hardness after 10 days of drying $\left(H_{\text {rel, } 10 \mathrm{~d}}\right)$; ${ }^{\mathrm{k}}$ not determined in ref. [16].

\subsection{In-situ FTIR spectroscopy}

Time-resolved FTIR spectroscopy was used for detailed investigation of catalytic activity of 3 . The autoxidation process was followed in situ on the $100 \mu \mathrm{m}$-coatings of alkyd formulation using classical transmission setup. Development of band at $3008 \mathrm{~cm}^{-1}$, assigned to $\mathrm{CH}$ stretching of non-conjugated cis- $\mathrm{CH}=\mathrm{CH}$ moiety (Figure 4), enabled to follow disappearance of reactive bis-allylic proton [34]. It was used for determination of kinetic parameters of the autoxidation process $\left(k_{\mathrm{CH} \text {,max }}\right.$, IT and $\left.t_{1 / 2}\right)$ at different metal concentration. The infrared spectra further show developments in region of $\mathrm{CH}$ wagging bands [35]. The rise of the band at $989 \mathrm{~cm}^{-1}$ reflects formation hydroperoxides with cis-trans conjugated double bond moiety (Figure 5). Intensity of the band reaches maximum at $t_{\mathrm{conj}}$ and then decreases as the radicals, appearing during autoxidation, 
add on reactive conjugated double bonds giving crosslinks between fatty acid chains [35]. Kinetic parameters, listed in Table 1, describing the autoxidation process were calculated according to previous studies [19].

The development of $\mathrm{CH}$ stretching band at $3008 \mathrm{~cm}^{-1}$ reveals rapid consumption of active cis- $\mathrm{CH}=\mathrm{CH}$ moieties in runs A-D (Figure 4). In this range of metal concentration, the half-life of the autoxidation process $\left(t_{1 / 2}\right)$ vary between 1.4 and $8.1 \mathrm{~h}$ that well correlates with data obtained by mechanical tests. The calculated rate coefficients $\left(k_{\mathrm{CH}, \max }\right)$ are lower than reported for cobalt(II) 2-ethylhexanoate at the same metal concentration but about twice of that previously reported for bispidine analogue without methyl groups in the pyridine rings [Fe ${ }^{\mathrm{II}}$ (bispi)OOCR][OOCR] ( $\mathrm{R}=$ 3-heptyl) [19]. We note that here reported formulations do not exhibit any signs of overdosing. Hence, $k_{\mathrm{CH} \text {,max }}$ and $t_{\text {conj }}$ fluently increase while induction time (IT) decreases with increasing metal concentration. In summary, the formulation $\mathbf{D}$ seems to be optimal for application as metal concentration is low (5 $\times 10^{-3}$ wt.\%) and the induction time of the autoxidation process is still acceptable. Further lowering the metal content (runs $\mathbf{E}$ and $\mathbf{F}$ ) led to deterioration of drying activity as evident from low values of $k_{\mathrm{CH} \text {,max }}$ and long induction times.

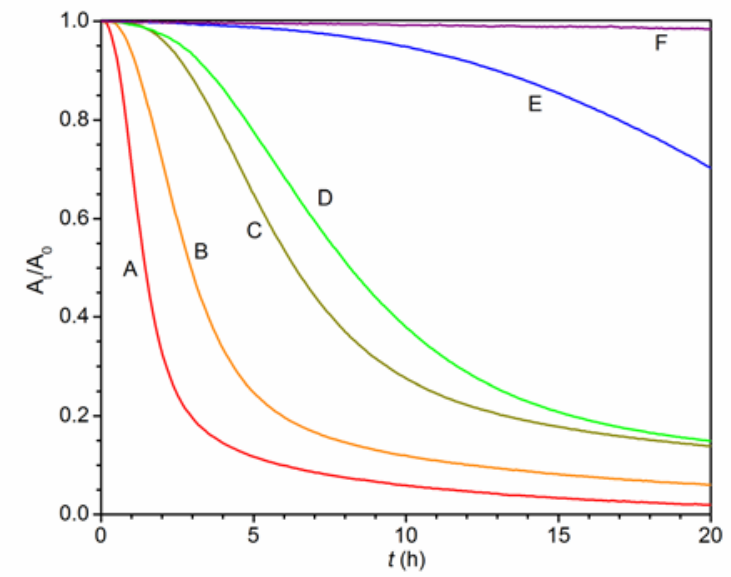

Fig. 4. Time dependent plots of the band at $3008 \mathrm{~cm}^{-1}$ for formulations $\mathbf{3} / \mathbf{S 6 0}$.

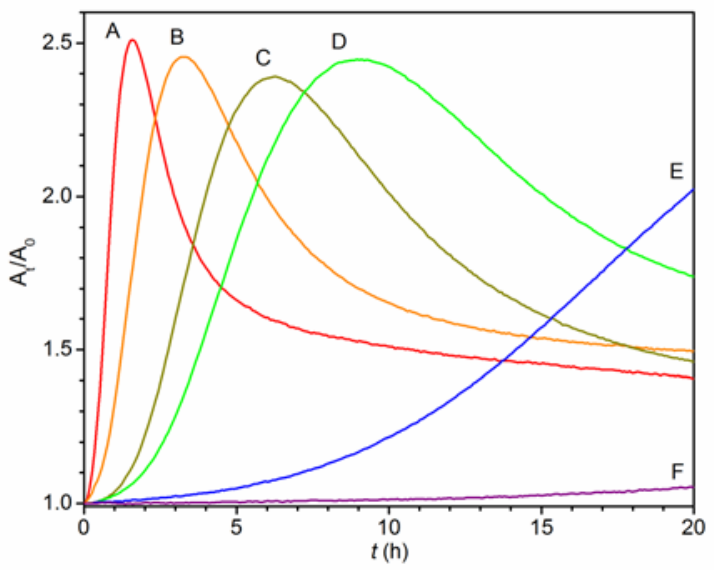

Fig. 5. Time dependent plots of the band at $989 \mathrm{~cm}^{-1}$ for formulations $\mathbf{3} / \mathbf{S 6 0}$. 


\section{Conclusions}

This study has described synthesis and catalytic activity of iron(II) complex bearing modified bispidine ligand (Mebispi). The synthetic part includes not only the characterization of final product (3) by spectroscopic methods and X-ray crystallography but also a detailed analysis of two reaction intermediates ( $\mathbf{1}$ and $\mathbf{2})$.

Catalytic activity of title compound (3) toward autoxidation of alkyd resins was determined by standard mechanic tests and detailed kinetic studies using time-resolved infrared spectroscopy. The excellent drying performance of the title compound (3) was demonstrated on formulations of slow-drying alkyd resin S60. The main advantage of the compound $\mathbf{3}$ is the excellent solubility in alkyd resin without necessity of pre-dissolution as usual in the case of currently used driers.

\section{Experimental section}

\subsection{Methods and material}

Iron(II) 2-ethylhexanoate [19] was prepared following method described elsewhere. All preparative reactions were carried out under inert atmosphere of argon on a Schlenk line. Solvent-borne phthalic-type alkyd resin modified with soybean oil CHS-Alkyd S $621 \mathrm{~W} 60$ (S60; oil length $=62$ wt.\%, dry matter $=60$ wt.\%, AN = 7 mg $\mathrm{KOH} / \mathrm{g}$ ) was supplied by Spolchemie. Metal concentrations are given in wt.\% based on dry matter of alkyd resin.

\subsection{Synthesis of 1}

Dimethyl-3-oxoglutarate $(4.732 \mathrm{~g} ; 27 \mathrm{mmol})$ was dissolved in methanol $(50 \mathrm{ml})$ precooled to $0^{\circ} \mathrm{C}$. The solution was treated with methylamine (2.94 g; $98 \mathrm{mmol}, 27 \%$ in water) dropwise. Appeared white precipitate was stirred at $0^{\circ} \mathrm{C}$ and treated with 6-methylpyridine-2-carboxaldehyde $(6.057 \mathrm{~g} ; 50 \mathrm{mmol})$. After the addition, precipitate dissolves to give orange-yellow solution. The solution was stirred for $10 \mathrm{~min}$ and then volatiles were vacuum evaporated. Crude product was dissolved in ethanol at cooled $-18^{\circ} \mathrm{C}$ overnight to give fine precipitate that was filtered off washed with cold diethyl ether and vacuum dried. Yield: $4.60 \mathrm{~g}$ (11 mmol, $45 \%$ ). Colorless solid. Mp. $138{ }^{\circ}$ C. Anal. Calcd. For $\left(\mathrm{C}_{22} \mathrm{H}_{25} \mathrm{~N}_{3} \mathrm{O}_{5}\right)$ : C, 64.22; H, 6.12; N, 10.21. Found: C, 64.50; H, 6.28; N, 10.05. ${ }^{1} \mathrm{H}-\mathrm{NMR}\left(500.16 \mathrm{MHz}, \mathrm{CDCl}_{3}, 4: 1\right.$ mixture of 1-enol/1-keto, numbering according to Fig. 1) $\delta$ for $\mathbf{1}$-enol: 12.41 (s, 1H, OH), $7.56\left(\mathrm{t},{ }^{3} \mathrm{~J}\left({ }^{1} \mathrm{H},{ }^{1} \mathrm{H}\right)=7.7 \mathrm{~Hz}, 1 \mathrm{H}, \mathrm{H}_{13,19}\right), 7.42\left(\mathrm{t},{ }^{3} \mathrm{~J}\left({ }^{1} \mathrm{H},{ }^{1} \mathrm{H}\right)=7.7 \mathrm{~Hz}, 1 \mathrm{H}, \mathrm{H}_{13,19}\right), 7.30(\mathrm{~d}$, $\left.{ }^{3} J\left({ }^{1} \mathrm{H},{ }^{1} \mathrm{H}\right)=7.7 \mathrm{~Hz}, 1 \mathrm{H}, \mathrm{H}_{14,20}\right), 7.02\left(\mathrm{~d},{ }^{3} J\left({ }^{1} \mathrm{H},{ }^{1} \mathrm{H}\right)=7.7 \mathrm{~Hz}, 2 \mathrm{H}, \mathrm{H}_{12,14,18,20}\right), 6.95\left(\mathrm{~d},{ }^{3} \mathrm{~J}\left({ }^{1} \mathrm{H},{ }^{1} \mathrm{H}\right)=7.7 \mathrm{~Hz}, 1 \mathrm{H}\right.$, $\left.\mathrm{H}_{12,14,18,20}\right), 4.81\left(\mathrm{~s}, 1 \mathrm{H}, \mathrm{H}_{3}\right), 4.47\left(\mathrm{~d},{ }^{3} J\left({ }^{1} \mathrm{H},{ }^{1} \mathrm{H}\right)=9.3 \mathrm{~Hz}, 1 \mathrm{H}, \mathrm{H}_{4}\right), 4.17\left(\mathrm{~d},{ }^{3} \mathrm{~J}\left({ }^{1} \mathrm{H},{ }^{1} \mathrm{H}\right)=9.3 \mathrm{~Hz}, 1 \mathrm{H}, \mathrm{H}_{5}\right), 3.73(\mathrm{~s}$, 3H, $\mathrm{H}_{7,9}$ ), 3.58 (s, 3H, $\mathrm{H}_{7,9}$ ), 2.56 (s, 3H, $\mathrm{H}_{15,21}$ ), 2.46 (s, 3H, $\mathrm{H}_{15,21}$ ), 2.19 (s, 3H, $\mathrm{H}_{22}$ ); $\delta$ for 1-keto: 7.51 (t, $\left.{ }^{3} J\left({ }^{1} \mathrm{H},{ }^{1} \mathrm{H}\right)=7.7 \mathrm{~Hz}, 2 \mathrm{H}, \mathrm{H}_{13,19}\right), 7.08\left(\mathrm{~d},{ }^{3} \mathrm{~J}\left({ }^{1} \mathrm{H},{ }^{1} \mathrm{H}\right)=7.7 \mathrm{~Hz}, 2 \mathrm{H}, \mathrm{H}_{12,14,18,20}\right), 7.03\left(\mathrm{~d},{ }^{3} \mathrm{~J}\left({ }^{1} \mathrm{H},{ }^{1} \mathrm{H}\right)=7.7 \mathrm{~Hz}, 2 \mathrm{H}\right.$, $\left.\mathrm{H}_{12,14,18,20}\right), 4.51\left(\mathrm{~d},{ }^{3} \mathrm{~J}\left({ }^{1} \mathrm{H},{ }^{1} \mathrm{H}\right)=5.9 \mathrm{~Hz}, 2 \mathrm{H}, \mathrm{H}_{3,4}\right), 4.05\left(\mathrm{~d},{ }^{3} \mathrm{~J}\left({ }^{1} \mathrm{H},{ }^{1} \mathrm{H}\right)=5.9 \mathrm{~Hz}, 2 \mathrm{H}, \mathrm{H}_{2,5}\right), 3.74\left(\mathrm{~s}, 6 \mathrm{H}, \mathrm{H}_{7,9}\right), 2.48$ (s, 6H, $\mathrm{H}_{15,21}$ ), 2.06 (s, 3H, $\mathrm{H}_{22}$ ). ${ }^{13} \mathrm{C}\left\{{ }^{1} \mathrm{H}\right\}$-NMR $\left(125.77 \mathrm{MHz}, \mathrm{CDCl}_{3}\right.$, 4:1 mixture of 1-enol/1-keto, numbering according to Fig. 1$) \delta$ for 1-enol: 172.1, $171.7\left(2 \times 1 \mathrm{C}_{q}, \mathrm{C}_{6,8}\right), 167.4\left(1 \mathrm{C}_{\mathrm{q}}, \mathrm{C}_{1}\right), 159.6,157.8\left(2 \times 1 \mathrm{C}_{q}, \mathrm{C}_{10,16}\right)$, $157.5\left(2 \mathrm{C}_{\mathrm{q}}, \mathrm{C}_{17,11}\right), 136.5,136.4\left(2 \times 1 \mathrm{C}, \mathrm{C}_{13,19}\right), 121.9,121.8,120.2,119.7\left(4 \times 1 \mathrm{C}, \mathrm{C}_{12,14,18,20}\right), 99.0\left(1 \mathrm{C}_{\mathrm{q}}, \mathrm{C}_{2}\right)$, 65.0 (1C, $\left.\mathrm{C}_{3}\right), 61.0$ (1C, $\left.\mathrm{C}_{4}\right), 52.4,51.8$ ( $\left.2 \times 1 \mathrm{C}, \mathrm{C}_{7,9}\right), 46.2\left(1 \mathrm{C}, \mathrm{C}_{5}\right), 38.0$ (1C, $\left.\mathrm{C}_{22}\right), 24.7,24.4\left(2 \times 1 \mathrm{C}, \mathrm{C}_{15,21}\right)$. ; $\delta$ for 1-keto: $197.3\left(1 \mathrm{C}_{\mathrm{q}}, \mathrm{C}_{1}\right), 169.3\left(2 \mathrm{C}_{\mathrm{q}}, \mathrm{C}_{6,8}\right), 158.3\left(2 \mathrm{C}_{\mathrm{q}}, \mathrm{C}_{11,17}\right), 156.6\left(2 \mathrm{C}_{\mathrm{q}}, \mathrm{C}_{10,16}\right), 136.7$ (2C, $\left.\mathrm{C}_{13,19}\right), 122.4$, 120.3 ( $2 \times 2 \mathrm{C}, \mathrm{C}_{12,14,18,20)}$ ) 66.9 (2C, $\left.\mathrm{C}_{3,4}\right), 59.3$ (2C, $\mathrm{C}_{2,5}$ ), 52.1 (2C, $\mathrm{C}_{7,9}$ ), 39.94 (1C, $\mathrm{C}_{22}$ ), 24.1 (2C, $\mathrm{C}_{15,21}$ ). IR $\left(A T R-C, \mathrm{~cm}^{-1}\right)$ : $1726 v s$ ( $\left.v_{\mathrm{C}=\mathrm{O}}, \mathrm{COOMe}\right), 1650 \mathrm{~s}\left(\delta_{\mathrm{O}-\mathrm{H}}\right.$, enol), $1621 \mathrm{~m}-\mathrm{s}\left(v_{\mathrm{C}=\mathrm{C}}\right.$, enol), $1590 \mathrm{~s}, 1574 \mathrm{~s}\left(2 \times v_{\mathrm{C}=\mathrm{C}}, \mathrm{py}\right)$. 
IR (ATR-C, cm $\left.{ }^{-1}\right): 1726 v_{s}\left(v_{\mathrm{C}=\mathrm{O}}, \mathrm{COOMe}\right), 1650 \mathrm{~s}\left(\delta_{\mathrm{O}-\mathrm{H}}\right.$, enol), 1621m-s $\left(v_{\mathrm{C}=\mathrm{C}}\right.$, enol), 1590s, $1574 \mathrm{~s}\left(2 \times v_{\mathrm{C}=\mathrm{C}}\right.$, py). IR $\left(\mathrm{CCl}_{4}, \mathrm{~cm}^{-1}\right): 1736 \mathrm{~s}\left(v_{\mathrm{C}=\mathrm{O}}, \mathrm{COOMe}\right), 1661 \mathrm{vs}\left(\delta_{\mathrm{O}-\mathrm{H}}, \mathrm{enol}\right), 1620 \mathrm{~m}\left(v_{\mathrm{C}=\mathrm{C}}\right.$, enol $), 1592 \mathrm{~m}, 1578 \mathrm{~s}\left(2 \times v_{\mathrm{C}=\mathrm{C}}\right.$, py). Raman (glass capillary, $\left.\lambda_{\text {exc. }}=1064 \mathrm{~nm}, \mathrm{~cm}^{-1}\right): 1730 \mathrm{~m}\left(v_{\mathrm{C}=\mathrm{O}}, \mathrm{COOMe}\right), 1623 \mathrm{~s}\left(v_{\mathrm{C}=\mathrm{C}}\right.$, enol), 1592s, 1577s $(2$ $\times v_{\mathrm{C}=\mathrm{C}}$, py). Single-crystals suitable for X-ray analysis were prepared by slow cooling of saturated solution in ethanol from room temperature to $-18^{\circ} \mathrm{C}$. UV-Vis [MeCN, $\left.\lambda_{\max }, \mathrm{nm}, \varepsilon, \log \left(\mathrm{M}^{-1} \cdot \mathrm{cm}^{-1}\right)\right]$ : 263 (4.03), 229sh (3.63).

\subsection{Synthesis of 2}

Compound 2 (4.60 g; $11 \mathrm{mmol}$ ) was dissolved in ethanol and treated with 2-(aminomethyl)pyridine (1.51 g; $14 \mathrm{mmol}$ ) and formaldehyde (33\% in water, $2.36 \mathrm{~g}$; $26 \mathrm{mmol}$ ). The reaction mixture was heated under reflux for 2.5 h. After cooling to room temperature, volatiles were vacuum evaporated to give viscous liquid. Crude product was dissolved in ethanol $(50 \mathrm{ml})$, overlayered with diethyl ether and stored at $-18^{\circ} \mathrm{C}$ overnight. White precipitate was filtered off, washed with diethyl ether and vacuum dried. Yield: $2.40 \mathrm{~g}$ (4.4 mmol, 40 \%). Mp. $223{ }^{\circ} \mathrm{C}$. Anal. Calcd. For $\left(\mathrm{C}_{30} \mathrm{H}_{33} \mathrm{~N}_{5} \mathrm{O}_{5}\right)$ : C, 66.28; H, 6.12; N, 12.88. Found: C, 66.02; H, 6.37; N, 12.55 . ${ }^{1} \mathrm{H}-$ NMR (500.16 MHz, $\mathrm{CDCl}_{3}$, numbering according to Fig. 2) $\delta: 8.62$ (d, $\left.{ }^{3} J\left({ }^{1} \mathrm{H},{ }^{1} \mathrm{H}\right)=4.5 \mathrm{~Hz}, 1 \mathrm{H}, \mathrm{H}_{5}\right), 7.75$ (d, $\left.{ }^{3} J\left({ }^{1} \mathrm{H},{ }^{1} \mathrm{H}\right)=7.5 \mathrm{~Hz}, 2 \mathrm{H}, \mathrm{H}_{8,14}\right), 7.66\left(\mathrm{td},{ }^{3} \mathrm{~J}\left({ }^{1} \mathrm{H},{ }^{1} \mathrm{H}\right)=7.5 \mathrm{~Hz},{ }^{4} \mathrm{~J}\left({ }^{1} \mathrm{H},{ }^{1} \mathrm{H}\right)=1.6 \mathrm{~Hz}, 1 \mathrm{H}, \mathrm{H}_{3}\right), 7.41\left(\mathrm{t},{ }^{3} \mathrm{~J}\left({ }^{1} \mathrm{H},{ }^{1} \mathrm{H}\right)=7.5\right.$ $\left.\mathrm{Hz}, 2 \mathrm{H}, \mathrm{H}_{9,15}\right), 7.28\left(\mathrm{~d},{ }^{3} \mathrm{~J}\left({ }^{1} \mathrm{H},{ }^{1} \mathrm{H}\right)=7.5 \mathrm{~Hz}, 1 \mathrm{H}, \mathrm{H}_{2}\right), 7.23\left(\mathrm{dd},{ }^{3} J\left({ }^{1} \mathrm{H},{ }^{1} \mathrm{H}\right)=7.5 \mathrm{~Hz},{ }^{3} J\left({ }^{1} \mathrm{H},{ }^{1} \mathrm{H}\right)=4.5 \mathrm{~Hz}, 1 \mathrm{H}, \mathrm{H}_{4}\right)$, $6.96\left(\mathrm{~d},{ }^{3} \mathrm{~J}\left({ }^{1} \mathrm{H},{ }^{1} \mathrm{H}\right)=7.5 \mathrm{~Hz}, 2 \mathrm{H}, \mathrm{H}_{10,16}\right), 4.63$ (s, 2H, $\left.\mathrm{H}_{24,25}\right), 3.82$ (s, 6H, H27,29), 3.54 (s, $\left.2 \mathrm{H}, \mathrm{H}_{6}\right), 3.03$ (d, $\left.{ }^{2} J\left({ }^{1} \mathrm{H},{ }^{1} \mathrm{H}\right)=12.0 \mathrm{~Hz}, 2 \mathrm{H}, \mathrm{H}_{19,23}\right), 2.62\left(\mathrm{~d},{ }^{2} \mathrm{~J}\left({ }^{1} \mathrm{H},{ }^{1} \mathrm{H}\right)=12.0 \mathrm{~Hz}, 2 \mathrm{H}, \mathrm{H}_{19,23}\right), 2.42\left(\mathrm{~s}, 6 \mathrm{H}, \mathrm{H}_{12,18}\right), 2.03\left(\mathrm{~s}, 3 \mathrm{H}, \mathrm{H}_{30}\right)$. ${ }^{13} \mathrm{C}\left\{{ }^{1} \mathrm{H}\right\}$-NMR (125.77 MHz, $\mathrm{CDCl}_{3}$, numbering according to Fig. 2): $\delta 203.9\left(1 \mathrm{C}_{\mathrm{q}}, \mathrm{C}_{21}\right), 168.8\left(2 \mathrm{C}_{\mathrm{q}}, \mathrm{C}_{26,28}\right)$,

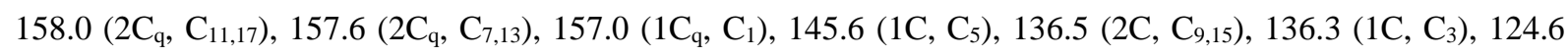
(2C, $\left.\mathrm{C}_{8,14}\right), 122.4$ (2C, $\left.\mathrm{C}_{10,16}\right), 122.3$ (1C, $\left.\mathrm{C}_{4}\right), 120.5$ (1C, $\left.\mathrm{C}_{2}\right), 73.8$ (2C, $\left.\mathrm{C}_{24,25}\right), 63.6\left(1 \mathrm{C}, \mathrm{C}_{6}\right), 62.5\left(2 \mathrm{C}_{\mathrm{q}}, \mathrm{C}_{20,22}\right)$, 58.9 (2C, $\mathrm{C}_{19,23}$ ), 52.3 (2C, $\mathrm{C}_{27,29}$ ), 24.5 (2C, $\mathrm{C}_{12,18}$ ). IR (ATR-C, $\left.\mathrm{cm}^{-1}\right): 1731 \mathrm{vs}, 1721 \mathrm{vs}\left(2 \times v_{\mathrm{C}=\mathrm{O}}, \mathrm{CO}, \mathrm{COOMe}\right)$, $1592 \mathrm{~s}, 1572 \mathrm{~s}\left(2 \times v_{\mathrm{C}=\mathrm{C}}\right.$, py). IR $\left(\mathrm{CCl}_{4}, \mathrm{~cm}^{-1}\right)$ : 1743s, 1733sh-s $\left(v_{\mathrm{C}=\mathrm{O}}, \mathrm{COOMe}\right), 1592 \mathrm{~m}, 1576 \mathrm{~m}\left(2 \times v_{\mathrm{C}=\mathrm{C}}, \mathrm{py}\right)$. Raman (glass capillary, $\left.\lambda_{\text {exc. }}=1064 \mathrm{~nm}, \mathrm{~cm}^{-1}\right)$ : 1734m, 1724m $\left(2 \times v_{\mathrm{C}=\mathrm{O}}, \mathrm{CO}\right.$, COOMe), 1593m, $1575 \mathrm{~m}(2 \times$ $\left.v_{\mathrm{C}=\mathrm{C}}, \mathrm{py}\right) . \mathrm{UV}-\mathrm{Vis}\left[\mathrm{MeCN}, \lambda_{\max }, \mathrm{nm}, \varepsilon, \log \left(\mathrm{M}^{-1} \cdot \mathrm{cm}^{-1}\right)\right]: 265$ (3.92), 232sh (3.43).

\subsection{Synthesis of 3}

Solid iron(II) 2-ethylhexanoate (1.59 g, $4.63 \mathrm{mmol})$ was treated with suspension of finely powdered 2 (1.68 g, $3.09 \mathrm{mmol})$ in deoxygenated acetonitrile $(50 \mathrm{ml})$. The mixture was stirred at ambient temperature until all starting materials were dissolved to give canary colored solution. The solution was filtered and volatiles were vacuum evaporated. Crude product was washed with diethyl ether $(3 \times 20 \mathrm{ml})$ and vacuum dried to give the final product as an $\mathrm{Et}_{2} \mathrm{O}$ solvate. Yield: $1.71 \mathrm{~g}$ (1.75 mmol, 57\%). Mp. $125{ }^{\circ} \mathrm{C}$ (dec). Anal. Calcd. For $\left(\mathrm{C}_{46} \mathrm{H}_{65} \mathrm{FeN}_{5} \mathrm{O}_{10} \cdot \mathrm{C}_{4} \mathrm{H}_{10} \mathrm{O}\right)$ : C, 61.40; H, 7.73; N, 7.15. Found: C, 61.30; H, 7.52; N, 7.36. The content of iron metal $(5.6 \pm 0.2 \%$, calc. $5.71 \%)$ has been determined by atomic absorption spectroscopy. Positive-ion MS $(\mathrm{MeCN}): \mathrm{m} / \mathrm{z}=742(100 \%)\left[\mathrm{M}-\mathrm{H}_{2} \mathrm{O}\right]^{+}, 760[\mathrm{M}]^{+}$. IR $\left(\mathrm{ATR}-\mathrm{C}, \mathrm{cm}^{-1}\right): 1732 \mathrm{~s}, 1722 \mathrm{vs}\left(2 \times v_{\mathrm{C}=\mathrm{O}}, \mathrm{COOMe}\right)$, $1626 \mathrm{~s}\left(\delta_{\mathrm{O}-\mathrm{H}}, \mathrm{diol}\right), 1602 \mathrm{~s}, 1572 \mathrm{~m}\left(2 \times v_{\mathrm{C}=\mathrm{C}}\right.$, py). IR $\left(\mathrm{CH}_{2} \mathrm{Cl}_{2}, \mathrm{~cm}^{-1}\right): 1728 \mathrm{br}-\mathrm{vs}\left(2 \times v_{\mathrm{C}=\mathrm{O}}, \mathrm{COOMe}\right), 1619 \mathrm{br}-\mathrm{m}$ $\left(\delta_{\mathrm{O}-\mathrm{H}}\right.$, diol $), 1604 \mathrm{~s}, 1575 \mathrm{~m}\left(2 \times v_{\mathrm{C}=\mathrm{C}}\right.$, py). Raman (glass capillary, $\left.\lambda_{\text {exc. }}=532 \mathrm{~nm}, \mathrm{~cm}^{-1}\right): 1602 \mathrm{~s}, 1573 \mathrm{~m}\left(2 \times v_{\mathrm{C}=\mathrm{C}}\right.$, py). $\mu_{\mathrm{eff}}=4.92 \pm 0.03$ B. M. (at $293 \mathrm{~K}$ ). Single crystals of $\mathbf{3} \cdot \mathrm{Et}_{2} \mathrm{O}$ suitable for X-ray analysis were prepared by 
careful overlayering of a solution in $\mathrm{CH}_{2} \mathrm{Cl}_{2}$ with $\mathrm{Et}_{2} \mathrm{O}$. UV-Vis [MeCN, $\left.\lambda \max , \mathrm{nm}, \varepsilon, \log \left(\mathrm{M}^{-1} \cdot \mathrm{cm}^{-1}\right)\right]$ : 400 (3.35), 264 (4.13), 230sh (3.68).

\subsection{Preparation of test coatings}

$52.5 \mathrm{mg}(53.7 \mu \mathrm{mol})$ and $105.1 \mathrm{mg}(107.5 \mu \mathrm{mol})$ of $\mathbf{3}$ was weighted on analytical balance, treated with alkyd resin $\mathbf{S 6 0}(10.0 \mathrm{~g})$ and stirred vigorously for $2 \mathrm{~min}$ with spatula to get clear solutions of metal concentration $5 \times$ $10^{-2}$ and $1 \times 10^{-1} \mathrm{wt} . \%$, respectively. Formulations of lower concentration were prepared by dilution. $1.00 \mathrm{~g}$ of given formulations was diluted with $9.00 \mathrm{~g}$ of $\mathbf{S 6 0}$ and homogenized to get a formulation of ten times lower concentration. The test coatings were prepared from freshly prepared formulation by frame applicators of given slot. The overall time of sample preparation did not exceed 15 min.

\subsection{Determination of drying times}

The drying performance of studied catalytic systems has been determined using a B. K. Drying Time Recorder (BYK). The instrument is a straight-line recorder equipped with hemispherical ended needle (5 g weight used). The needle travels the length of the test strip under standard laboratory conditions $\left(\mathrm{T}=23^{\circ} \mathrm{C}\right.$, rel. humidity 50\%). Glass test strip $(305 \times 25 \times 2 \mathrm{~mm})$ was prepared by casting a film upon it (thickness of wet film was $76 \mu \mathrm{m})$. The trace left on the film during the drying has been used to define tack free time $\left(\tau_{1}\right)$ and total dry time $\left(\tau_{2}\right)$. During the stage $1\left(\mathrm{t}=0-\tau_{0}\right)$, the paint flows together and starts to polymerize. It gives bold and uninterrupted line. During the stage $2\left(t=\tau_{1}-\tau_{2}\right)$, the surface is sticky and the path is ripped. After $\tau_{2}$ (stage 3$)$ the paint is through dry and needle travels on top of the surface and no trace in the film is observable.

\subsection{Determination of film hardness}

Film hardness development was monitored using a Persoz type pendulum (Elcometer Pendulum Hardness Tester, UK) in conformity with ISO 1522. The method is based on registering the number of pendulum swings it takes before the amplitude of the pendulum is damped to a certain extent [36]. The more swing observed, the harder is the film. Plain glass test plate $(200 \times 100 \times 4 \mathrm{~mm})$ was coated with a $150 \mu \mathrm{m}$ film (wet thickness) dried with the appropriate drier system and film hardness was measured within 100 days. The measured value was related to the hardness of a glass standard (limit value of the pendulum test) and expressed as relative hardness. The error in determination of surface hardness was estimated to be $0.5 \%$.

\subsection{Mass spectrometry}

Positive-ion electrospray ionization (ESI) mass spectra were recorded on a quadruple mass spectrometer (LCMS 2010, Shimadzu, Japan). The sample was injected into the mass spectrometer with infusion mode at a constant flow rate of $10 \mu \mathrm{l} / \mathrm{min}$. Electrospray ionization-mass spectrometry (ESI-MS) was used for the identification of analyzed samples.

\subsection{NMR spectroscopy}


${ }^{1} \mathrm{H}$ and ${ }^{13} \mathrm{C}\{1 \mathrm{H}\}$ NMR spectra were measured on a NMR spectrometer JNM-ECZ500R (Jeol) at room temperature. The chemical shifts are given in ppm relative to TMS. ${ }^{13} \mathrm{C}-\mathrm{DEPT} 135$ and 2D techniques $\left({ }^{1} \mathrm{H}-{ }^{1} \mathrm{H}\right.$ COSY, HSQC and HMBC) were used for assignment of signals in ${ }^{1} \mathrm{H}$ and ${ }^{13} \mathrm{C}\{1 \mathrm{H}\}$ NMR spectra.

\subsection{Infrared spectroscopy}

Infrared spectra of solid samples were measured on a Nicolet iS50 FTIR spectrometer in the 4000-400 cm-1 region (32 scans, data spacing $0.5 \mathrm{~cm}^{-1}$ ) using Diamond Smart Orbit ATR. The autoxidation of alkyd resin was followed by time-resolved FTIR on spectrophotometer Nicolet 6700 (32 scans per spectrum, data spacing of 0.5 $\mathrm{cm}^{-1}$ ) in the range of 4000-500 $\mathrm{cm}^{-1}$. Mixture of alkyd resin with appropriate drier was spread on the $\mathrm{NaCl}$ plate using an applicator with slot width $100 \mu \mathrm{m}$. Sample was placed in the spectrometer and IR spectrum was recorded each $5 \mathrm{~min}$ at $23^{\circ} \mathrm{C}$. Collected IR spectra were integrated using fixed two-point baseline in the region 3014-2997 $\mathrm{cm}^{-1}$ (cis- $\mathrm{C}=\mathrm{C}-\mathrm{H}$ stretch). Rate coefficients $\left(-k_{\mathrm{CH}, \max }\right)$ at the beginning of the autoxidation process were estimated as the steepest slope of the logarithmic plot of the integrated area vs. time. The error in determination of $k_{\mathrm{CH} \text {,max }}$ was less than $10 \%$ (three independent measurements for each run). The intensity of bands at $989 \mathrm{~cm}^{-1}$ was determined as the absorbance at this wavenumbers using linear baseline fixed at wavenumbers 1010 and $945 \mathrm{~cm}^{-1}$.

\subsection{Raman spectroscopy}

Raman spectra were measured on a Nicolet iS50 FTIR spectrometer equipped with Raman module in the 4000-100 $\mathrm{cm}^{-1}$ region (data spacing $2 \mathrm{~cm}^{-1}$ ) in glass capillaries. The excitation source consisted of Nd:YAG laser emitting at $1064 \mathrm{~cm}^{-1}$ and Horiba Jobin Yvon Raman spectrometer $\left(\lambda_{\text {exc. }}=532 \mathrm{~nm}\right)$.

\section{$4.12 U V$-vis spectroscopy}

Electronic absorption spectra (200-1080 nm) of acetonitrile solutions of 1-3 were run on a Black-Comet CSR-100 concave grating spectrometer in $1 \mathrm{~cm}$ quartz cuvettes.

\subsection{X-ray crystallography}

The X-ray data for crystals of $\mathbf{1}$-enol and $\mathbf{3} \cdot \mathrm{Et}_{2} \mathrm{O}$ were obtained at $150 \mathrm{~K}$ using Oxford Cryostream lowtemperature device on a Nonius KappaCCD diffractometer with Mo/K $\mathrm{K}_{\alpha}$ radiation $(\lambda=0.71073 \AA$ ), a graphite monochromator, and the $\phi$ and $\chi$ scan mode. Data reductions were performed with DENZO-SMN [37]. The absorption was corrected by integration methods [38]. Structures were solved by direct methods (Sir92) [39] and refined by full matrix least-square based on $F^{2}$ (SHELXL97) [40]. Hydrogen atoms were mostly localized on a difference Fourier map, however to ensure uniformity of treatment of crystal, all hydrogen were recalculated into idealized positions (riding model) and assigned temperature factors $\mathrm{H}_{\text {iso }}(\mathrm{H})=1.2 \mathrm{U}_{\text {eq }}$ (pivot atom) or of $1.5 \mathrm{U}_{\text {eq }}$ (methyl). $\mathrm{H}$ atoms in methyl, methylene, methine, vinylidene moieties and hydrogen atoms in aromatic rings were placed with C-H distances of $0.96,0.97,0.98,0.93$ and $0.93 \AA$ and 0.86 or $0.82 \AA$ for $\mathrm{N}-\mathrm{H}$ or $\mathrm{O}-\mathrm{H}$ bonds.

The structure of $3 \cdot \mathrm{Et}_{2} \mathrm{O}$ contains positional static disorder of two 2-ethylhexanoate group, this disorder was treated by standard procedures implemented in SHELXL software and atoms were split into two positions with equal occupancy [41]. 


\section{Appendix A. Supplementary data}

CCDC 1871158 and CCDC 1871159 contain the supplementary crystallographic data for $\mathbf{1}$ and $\mathbf{3} \cdot \mathbf{E t}_{\mathbf{2}} \mathbf{O}$.

These data can be obtained free of charge via http://www.ccdc.cam.ac.uk/conts/retrieving.html, or from the Cambridge Crystallographic Data Centre, 12 Union Road, Cambridge CB2 1EZ, UK; fax: (+44) 1223-336-033; or e-mail: deposit@ccdc.cam.ac.uk.

\section{References}

[1] P. Comba, M. Kerscher, W. Schiek, Prog. Inorg. Chem. 55 (2007) 613-704.

[2] P. Comba, M. Kerscher, T. Krause, H. F. Schöler, Environ. Chem. 12 (2015) 381-395.

[3] R. Hage, P. V. Wesenhagen, Liquid Hardening. International Patent US 2011/0277665 A1 (Nov. 17, 2011).

[4] J. W. de Boer, P. V. Wesenhagen, E. C. M. Wenker, K. Maaijen, F. Gol, H. Gibbs, R. Hage, Eur. J. Inorg. Chem. (2013) 3581-3591.

[5] M. Moreno, C. Lampard, N. Williams, E. Lago, S. Emmett, M. Goikoetxea, M. J. Barandiaran, Prog. Org. Coat. 81 (2015) 101-106.

[6] C. J. Patel, V. Mannari, Prog. Org. Coat. 77 (2014) 997-1006.

[7] D. Lison, M. De Boeck, V. Verougstraete, M. Kirsch-Volders, Occup. Environ. Med. 58 (2001) 619625.

[8] M. De Boeck, M. Kirsch-Volders, D. Lison, Mutat. Res. 533 (2003) 135-152.

[9] R. van Gorkum, E. Bouwman, J. Reedijk, Inorg. Chem. 43 (2004) 2456-2458.

[10] E. Bouwman, R. van Gorkum, J. Coat. Technol. Res. 4 (2007) 491-503.

[11] Z. O. Oyman, W. Ming, R. van der Linde, Appl. Catal. A 316 (2007) 191-196.

[12] F. Micciche, E. Oostveen, J. van Haveren, R. van der Linde, Prog. Org. Coat. 53 (2005) 99-105.

[13] M. Erben, D. Veselý, J. Vinklárek, J. Honzíček, J. Mol. Catal. A: Chem. 353-354 (2012) 13-21.

[14] J. Honzíček, J. Vinklárek, J. Appl. Polym. Sci. 135 (2018) 46184.

[15] O. Preininger, J. Vinklárek, J. Honzíček, T. Mikysek, M. Erben, Prog. Org. Coat. 88 (2015) 191-198.

[16] O. Preininger, J. Honzíček, P. Kalenda, J. Vinklárek, J. Coat. Technol. Res. 13 (2016) 479-487.

[17] O. Preininger, I. Charamzová, J. Vinklárek, I. Císařová, J. Honzíček, Inorg. Chim. Acta 462 (2017) 1622.

[18] I. Charamzová, J. Vinklárek, P. Kalenda, J. Honzíček, Coatings 8 (2018) 204.

[19] M. Křižan, J. Vinklárek, M. Erben, I. Císařová, J. Honzíček, Prog. Org. Coat. 111 (2017) 361-370.

[20] I. Charamzová, J. Vinklárek, J. Honzíček, Prog. Org. Coat. 125 (2018) 177-185.

[21] Ö. Gezici-Koç, C. A. A. M. Thomas, M. E. B. Michel, S. J. F. Erich, H. P. Huinink, J. Flapper, F. L. Duivenvoorde, L. G. J. van der Ven, O. C. G. Adan, Mater. Today Commun. 7 (2016) 22-31.

[22] U. Holzgrabe, E. Erciyas, Arch. Pharm. 325 (1992) 657-663.

[23] P. Comba, C. L. de Laorden, H. Pritzkow, Helv. Chim. Acta 88 (2005) 647-664.

[24] N. A. Barnes, A. T. Brooker, S. M. Godfrey, P. R. Mallender, R. G. Pritchard, M. Sadler, Eur. J. Org. Chem. (2008) 1019-1030.

[25] P. Comba, M. Morgen, H. Wadepohl, Inorg. Chem. 52 (2013) 6481-6501.

[26] G. Socrates, Infrared and Raman Characteristic Group Frequencies: Tables and Charts, 3rd ed., John Wiley \& Sons, Chichester, 2004.

[27] H. Börzel, P. Comba, K. S. Hagen, Y. D. Lampeka, A. Lienke, G. Linti, M. Merz, H. Pritzkow, L. V. Tsymbal, Inorg. Chim. Acta 337 (2002) 407-419.

[28] P. Comba, S. Kuwata, G. Linti, M. Tarnai, H. Wadepohl, Eur. J. Org. Chem. (2007) 657-664.

[29] M. Atanasov, P. Comba, S. Helmle, D. Müller, F. Neese, Inorg. Chem. 51 (2012) 12324-12335.

[30] P. Comba, H. Rudolf, H. Wadepohl, Dalton Trans. 44 (2015) 2724-2736.

[31] I. Prat, A. Company, T. Corona, T. Parella, X. Ribas, M. Costas, Inorg. Chem. 52 (2013) 9229-9244.

[32] ASTM D5895-03, Standard Test Methods for Evaluating Drying or Curing During Film Formation of Organic Coatings Using Mechanical Recorders, ASTM International, West Conshohocken, PA, 2003.

[33] ISO 1522:2006, Paints and varnishes - Pendulum damping test, International Organization for Standardization, 2006.

[34] F. R. van de Voort, A. A. Ismail, J. Sedman, G. Emo, J. Am. Oil Chem. Soc. 71 (1994) 243-253.

[35] Z. O. Oyman, W. Ming, R. van der Linde, Prog. Org. Coat. 48 (2003) 80-91.

[36] B. Persoz, Peintures, Pigments, Vernis 21 (1945) 194-201.

[37] Z. Otwinowski, W. Minor, Methods Enzymol. 276 (1997) 307-326. 
[38] P. Coppens, in Crystallographic Computing (Eds.: F. R. Ahmed, S. R. Hall, C. P. Huber), Munksgaard, Copenhagen, 1970, pp. 255-270.

[39] A. Altomare, G. Cascarano, C. Giacovazzo, A. Guagliardi, J. Appl. Cryst. 27 (1994) 1045-1050.

[40] G. M. Sheldrick, Acta Cryst. A71 (2015) 3-8.

[41] G. M. Sheldrick, SHELXL97, University of Göttingen, Germany (2008). 